\title{
Editorial
}

\section{Pediatric and Neonatal Malnutrition: A Collaborative, Family-Centered Approach Improves Outcomes}

\author{
Dena L. Goldberg, PhD, RDN'"; Holly A.Van Poots, RDN,CSP, FAND ${ }^{2}$ \\ 'Clinical Dietitian II, Carilion Children's, 1906 Belleview Avenue, Roanoke,VA 240 I 4, USA \\ ${ }^{2}$ Be Balanced Nutrition, LLC, 620 Neff Avenue, Harrisonburg, VA 2280I, USA \\ ${ }^{*}$ Corresponding author \\ Dena L. Goldberg, PhD, RDN \\ Clinical Dietitian II, Carilion Children's, 1906 Belleview Avenue, Roanoke,VA 240I4, USA; E-mail: dlgoldberg@carilionclinic.org
}

\section{Article information}

Received: December 3 ${ }^{\text {rd }}$, 2018; Revised: December 27 ${ }^{\text {th }}$, 2018; Accepted: December 28 ${ }^{\text {th }}$, 2018; Published: January $3^{\text {rd }}, 2019$

Cite this article

Goldberg DL,Van Poots HA. Pediatric and neonatal malnutrition:A collaborative, family-centered approach improves outcomes. Pediatr Neonatal Nurs Open J. 2019; 6(I): el-e4. doi: 10.17I40/PNNOJ-6-e008

\begin{abstract}
A ssessment of nutritional status and ensuring adequate nutrient Aintake are essential components of health care for infants and children who are ill. Pediatric malnutrition is defined as "an imbalance between nutrient requirement and intake, resulting in cumulative deficits of energy, protein, or micronutrients that may negatively affect growth, development, and other relevant outcomes." It is either illness-related or caused by social/environmental factors that result in decreased nutrient intake. It is classified as acute (less than 3 months) or chronic (greater than 3 months) in duration. ${ }^{1}$
\end{abstract}

Malnutrition should be documented and treated for several reasons. ${ }^{2}$ Although malnutrition is common-especially among hospitalized children with acute or chronic illness, special health care needs, and socio-environmental issues such as abuse, homelessness, or limited access to high quality nutritious food ${ }^{3,4}$ -its true prevalence is underreported and not well understood. According to Healthcare Cost and Utilization Project data from 2002-2011, 2.6\% of children hospitalized annually received a coded diagnosis of malnutrition; and overall prevalence increased by $8 \%$ annually during the same time frame. ${ }^{3}$ Previous studies using criteria other than coded diagnosis of malnutrition have reported a prevalence of $6 \%$ to $51 \% .{ }^{1}$ Very low-birth-weight infants are also at high risk for malnutrition due to increased nutrient requirements and altered nutrient utilization related to an immature gastrointestinal tract. Research indicates extrauterine growth failure, usually defined as weight less than the $10^{\text {th }}$ percentile at discharge or 3640 weeks, is common in preterm infants. ${ }^{5-7}$ Awareness of pediatric undernutrition by health care providers has increased over the past 5 years; yet without an accurate understanding of malnutrition prevalence during infancy and childhood, the clinical significance and associated costs are difficult to quantify.

Malnutrition increases consumption of health care resources due to its association with adverse outcomes. These adverse outcomes can range in severity and have lifelong repercussions in some cases: loss of lean body mass, muscle weakness, developmental/intellectual delays, infections, immune dysfunction, delayed wound healing, prolonged length of hospital stay, and even death. ${ }^{1,3,8}$ Optimal nutrition can also ameliorate medical complications of prematurity that are associated with increased length of stay and costs.

Diagnosing malnutrition can increase reimbursement for hospital care for an individual patient and over time increases the acuity factor for the facility. ${ }^{2}$ ICD-10 codes E44.1 (mild protein/ calorie malnutrition), E44.0 (moderate protein/calorie malnutrition), and E43.0 (severe protein/calorie malnutrition) should be used in place of P92.6 (failure to thrive). Even if reimbursement is not increased, malnutrition should be identified, evaluated, treated and monitored for optimal long term outcomes. Malnutrition added to the problem list on the discharge summary will inform the medical staff following the patient post discharge to continue focus on the correction of growth deficiencies. Nutrition affects growth and development and can have lifelong impact. ${ }^{9}$ The first 1,000 days of life is the peak time for brain development, and brain development is dependent on optimal nutrition. Research indicates that there are critical periods in brain development that depend on the availability of specific nutrients and that later supplementation cannot make up the deficit. ${ }^{2}$ A strong relationship between nutrition, brain growth, and neurodevelopmental outcomes exists. Several studies have demonstrated a link between poor growth and neurocognitive development up to 19 years of age. ${ }^{5,10-22}$ Early aggressive nutrition during the first two weeks of life promotes better brain growth and accelerated white matter maturation and promotes better growth. ${ }^{23-27}$ Poor head growth during the NICU stay and post discharge has been associated with motor and cognitive delays. ${ }^{28}$ Catch-up in weight and head growth after 36 weeks improves neurodevelopmental outcomes. ${ }^{6,728}$ Research supports a link between length, brain development, and neurocognitive outcome. ${ }^{16,17,19,29-31}$ This link is reinforced by body composition studies that have revealed less lean body mass with similar fat mass in preterm infants, even late preterm infants, at hospital discharge compared to term infants. ${ }^{32-35}$ This linear growth failure combined with expected fat mass accretion suggests that a decline in length $z$ 
scores or inadequate linear growth velocity is an important indicator of malnutrition in preterm infants and neonates. Early monitoring of growth to detect growth deficits is a strategy for improving growth outcomes. ${ }^{24}$

The most rapid growth phase in the life cycle occurs in preterm infants and neonates and they are most vulnerable to calorie, protein, and nutrient deficits during this time.Variations in growth rates between NICUs can be attributed to variations in nutrition practices. ${ }^{36-44}$ There is substantial research that supports the fact that nutrition practices impact growth and that extrauterine growth failure can be ameliorated or prevented. ${ }^{36-42,44-47}$

In 2014 the Academy of Nutrition and Dietetics and the American Society for Parenteral and Enteral Nutrition published a consensus statement with recommended indicators for identification of pediatric malnutrition in children 1 month of age to 18 years of age. ${ }^{4}$ The indicators describe criteria for mild, moderate, and severe malnutrition based on weight, length, BMI, weight for height, mid-upper arm circumference and nutrient intake. Preterm infants and neonates less than 28 days are not included. To fill this gap, the Pediatric Nutrition Practice Group of the Academy of Nutrition and Dietetics published recommended indicators for identifying malnutrition in preterm infants and neonates in $2018 .{ }^{48}$ The indicators also describe criteria for mild, moderate, and severe malnutrition using weight, length, and nutrient intake.

Identification of malnutrition starts with nutrition screening which is often completed by nurses. Nutrition screening, although conducted through different processes at different institutions, has the shared goal of identifying malnutrition risk in a timely manner so that a nutrition care plan can be implemented to prevent further deterioration in nutrition status and subsequent unfavorable outcomes. Because nurses and nursing staff have early and consistent contact with pediatric and neonatal patients and their families, their role in the process of nutrition screening, identification, documentation, and implementation of treatment plans for malnutrition should not be understated. From the initial physical exam when signs and symptoms of muscle wasting and subcutaneous fat loss may be observed; to assistance with feeding, bathing, dressing, and other activities of daily living when delays and changes from a child's baseline functional status may be noted; to facilitating consults and referrals for clinical nutrition services; to noticing the affect and interactions of caregivers with their children throughout the course of bedside care; to the rapport that is developed between nursing staff and families and also with the entire health care team; to obtaining and documenting accurate anthropometric measures used in malnutrition assessment as well as in monitoring and evaluation of the care plan; to ensuring the timely and appropriate administration of nutrition orders; the list of ways in which nurses and nursing staff are essential to the nutrition care process goes on and on. For one example, accuracy of the diagnosis of malnutrition is dependent on precise anthropometric measurements obtained using recommended technique and equipment. Length measurements obtained using a nonstandard length board or a tape measure are frequently inaccurate when compared with measurements obtained using recommended equipment and technique. ${ }^{49}$ Valid length measurements can increase the number of infants identified with growth abnormalities. ${ }^{50}$ Nurses may be the first member of the health care team to recognize red flags and other malnutrition risk factors, they often have the best sense of family dynamics, and they are indispensable allies for pediatric and neonatal registered dietitian nutritionists in our quest to create optimal health for infants, children, and adolescents through the healing power of food and nutrition.

The identification and documentation of pediatric undernutrition, especially illness-related malnutrition often seen in acute care as well as hospital ambulatory care settings, is a multistep process. Recommended indicators are evidence-informed and consensus-derived, and a validation effort is currently underway with the Malnutrition Clinical Characteristics Validation and Staffing Optimization Study by the Academy of Nutrition and Dietetics. In addition to evaluating the predictive validity of the indicators in relation to patient outcomes, interrater reliability and quantification of nutrition care associated with improved inpatient outcomes will be evaluated. ${ }^{51}$ As a result; we will undoubtedly see future changes to the process. The goal to identify malnutrition risk sooner, intervene earlier, and prevent adverse outcomes will not change. Nor will the fact that effective management of pediatric and neonatal malnutrition requires collaborative, interdisciplinary, and patient-centered interventions. All members of the health care team must recognize the impact of malnutrition on quality of life, on both developmental and treatment outcomes, and on reimbursement for services. They must recognize the urgency surrounding early identification and treatment of undernutrition in all patient populations from preterm infants to adolescents and on into adulthood. New research is needed in establishing interdisciplinary protocols for screening, diagnosis, treatment, and coding. More data is needed on prevalence for national benchmarking in order to evaluate trends and measure the effects of interventions. Keeping up with the changing landscape of malnutrition might seem overwhelming or even unnecessary at times. But pediatric malnutrition is one thing we can't afford to overlook on any day or any shift.

\section{REFERENCES}

1. Mehta NM, Corkins MR, Lyman B, et al. Defining pediatric malnutrition: A paradigm shift toward etiology-related definitions. J Parenter Enter Nutr. 2013; 37(4): 460-481. doi: $10.1177 / 0148607113479972$

2. Corkins MR. Why is diagnosing pediatric malnutrition important?. Nutr Clin Pract. 2017; 32(1): 15-18. doi: $10.1177 / 0884533616678767$

3. Carvalho-Salemi J, Salemi JL, Wong-Vega MR, et al. Malnutrition among hospitalized children in the United States: Changing prevalence, clinical correlates, and practice patterns between 2002 and 2011. J Acad Nutr Diet. 2018; 118: 40-51. e7. doi: 10.0.3.248/j. jand.2017.02.015

4. Becker PJ, Nieman Carney L, Corkins MR, et al. Consensus statement of the Academy of Nutrition and Dietetics/American Society for Parenteral and Enteral Nutrition: Indicators recom- 
mended for the identification and documentation of pediatric malnutrition (undernutrition). J Acad Nutr Diet. 2014; 114: 1988-2000. doi: 10.0.3.248/j.jand.2014.08.026

5. Ehrenkranz RA, Dusick AM, Vohr BR, Wright LL, Wrage LA, Poole WK. Growth in the neonatal intensive care unit influences neurodevelopmental and growth outcomes of extremely low birth weight infants. Pediatrics. 2006; 117(4): 1253-1261. doi: 10.1542/ peds. $2005-1368$

6. Shah PS, Wong KY, Merko S, et al. Postnatal growth failure in preterm infants: Ascertainment and relation to long-term outcome. J Perinat Med. 2006; 34(6): 484-489. doi: 10.1515/JPM.2006.094

7. Zozaya C, Díaz C, Saenz de Pipaón M. How should we define postnatal growth restriction in preterm infants?. Neonatology. 2018; 114(2): 177-180. doi: 10.0.4.135/000489388

8. Compher C, Mehta NM. Diagnosing malnutrition: Where are we and where do we need to go? J Acad Nutr Diet. 2016; 116: 779-784. doi: 10.0.3.248/j.jand.2016.02.001

9. Georgieff MK, Ramel SE, Cusick SE. Nutritional influences on brain development. Acta Paediatr. 2018; 107(8): 1310-1321. doi: 10.1111/apa.14287

10. Weisglas-Kuperus N, Hille ETM, Duivenvoorden HJ, et al. Intelligence of very preterm or very low birthweight infants in young adulthood. Arch Dis Child Fetal Neonatal Ed. 2009; 94(3): F196F200. doi: 10.1136/adc.2007.135095

11. Latal-Hajnal B, von Siebenthal K, Kovari H, Bucher HU, Largo RH. Postnatal growth in VLBW infants: Significant association with neurodevelopmental outcome. J Pediatr. 2003; 143(2): 163 170. doi: 10.1067/S0022-3476(03)00243-9

12. Kan E, Roberts G, Anderson PJ, Doyle LW. The association of growth impairment with neurodevelopmental outcome at eight years of age in very preterm children. Early Hum Dev. 2008; 84: 409-416. doi: 10.0.3.248/j.earlhumdev.2007.11.002

13. Franz AR, Pohlandt F, Bode H, et al. Intrauterine, early neonatal, and postdischarge growth and neurodevelopmental outcome at 5.4 years in extremely preterm infants after intensive neonatal nutritional support. Pediatrics. 2009; 123(1): e101-e109. doi: 10.1542/ peds.2008-1352

14. Benson Szekely LJ, Thompson M. Nutrition assessment. In: Groh-Wargo S, Thompson M, Hovasi Cox J, eds. Academy of Nutrition and Dietetics Pocket Guide to Neonatal Nutrition, ${ }^{\text {nd }}$ Edn . Chicago, IL: 2016: 1-31.

15. Claas MJ, de Vries LS, Koopman C, et al. Postnatal growth of preterm born children $\leq 750 \mathrm{~g}$ at birth. Early Hum Dev. 2011; 87: 495-507. doi: 10.1016/j.earlhumdev.2011.04.009

16. Belfort MB, Rifas-Shiman S, Sullivan T, et al. Infant growth before and after term: Effects on neurodevelopment in preterm infants. Pediatrics. 2011; 128(4): e899-e906. doi: 10.1542/peds.20110282

17. Ramel SE, Demerath EW, Gray HL, Younge N, Boys C, Georgieff MK. The relationship of poor linear growth velocity with neonatal illness and two-year neurodevelopment in preterm infants. Neonatology. 2012; 102(1): 19-24. doi: 10.1159/000336127

18. Leppanen M, Lapinleimu H, Lind A, et al. Antenatal and postnatal growth and 5-year cognitive outcome in very preterm infants. Pediatrics. 2014; 133(1): 63-70. doi: 10.1542/peds.2013-1187

19. Belfort MB, Gillman MW, Buka SL, Casey PH, McCormick MC. Preterm infant linear growth and adiposity gain: Trade-Offs for later weight status and intelligence quotient. J Pediatr. 2013; 163 : 1564-1569. e2. doi: 10.1016/j.jpeds.2013.06.032

20. Sammallahti S, Pyhälä R, Lahti $M$, et al. Infant growth after preterm birth and neurocognitive abilities in young adulthood. $J \mathrm{Pe}_{\text {- }}$ diatr. 2014; 165: 1109-1115. e3. doi: 10.0.3.248/j.jpeds.2014.08.028

21. Ong KK, Kennedy K, Castaneda-Gutierrez E, et al. Postnatal growth in preterm infants and later health outcomes: A systematic review. Acta Paediatr. 2015; 104(10): 974-986. doi: 10.1111/ apa. 13128

22. Chien H-C, Chen C-H, Wang T-M, Hsu Y-C, Lin M-C. Neurodevelopmental outcomes of infants with very low birth weights are associated with the severity of their extra-uterine growth retardation. Pediatr Neonatol. 2017. doi: 10.0.3.248/j.pedneo.2017.08.003

23. Schneider J, Fischer Fumeaux CJ, Duerden EG, et al. Nutrient intake in the first two weeks of life and brain growth in preterm neonates. Pediatrics. 2018; 141(3). pii: e20172169. doi: 10.1542/ peds.2017-2169

24. Genoni G, Binotti M, Monzani A, et al. Nonrandomised interventional study showed that early aggressive nutrition was effective in reducing postnatal growth restriction in preterm infants. Acta Paediatr. 2017; 106(10): 1589-1595. doi: 10.1111/apa.13958

25. Stephens BE, Walden R V, Gargus RA, et al. First-week protein and energy intakes are associated with 18-month developmental outcomes in extremely low birth weight infants. Pediatrics. 2009; 123(5): 1337-1343. doi: 10.1542/peds.2008-0211

26. Hiltunen H, Löyttyniemi E, Isolauri E, Rautava S. Early nutrition and growth until the corrected age of 2 years in extremely preterm infants. Neonatology. 2018; 113(2): 100-107. doi: $10.1159 / 000480633$

27. Paviotti G, De Cunto A, Zennaro F, et al. Higher growth, fat and fat-free masses correlate with larger cerebellar volumes in preterm infants at term. Acta Paediatr. 2017; 106(6): 918-925. doi: 10.1111/apa.13829

28. Raghuram K, Yang J, Church PT, et al. Head growth trajectory and neurodevelopmental outcomes in preterm neonates. Pediatrics. 
2017; 140(1): 1-10. doi: 10.1542/peds.2017-0216

29. Pfister KM, Gray HL, Miller NC, Demerath EW, Georgieff MK, Ramel SE. Exploratory study of the relationship of fat-free mass to speed of brain processing in preterm infants. Pediatr Res. 2013; 74(5): 576-583. doi: 10.1038/pr.2013.138

30. Pfister KM, Ramel SE. Linear growth and neurodevelopmental outcomes. Clin Perinatol. 2014; 41: 309-321. doi: 10.1016/j. clp.2014.02.004

31. Watanabe Y, Itabashi K, Taki M, Miyazawa T, Nakano Y, Murase $\mathrm{M}$. Body length and occipitofrontal circumference may be good indicators of neurodevelopment in very low birthweight infants - secondary publication. Acta Paediatr. 2018; 107(6): 975-980. doi: $10.1111 /$ apa.14250

32. Ramel SE, Gray HL, Ode KL, Younge N, Georgieff MK, Demerath EW. Body composition changes in preterm infants following hospital discharge: comparison with term infants. $J$ Pediatr Gastroenterol Nutr. 2011; 53(3): 333-338. doi: 10.1097/ MPG.0b013e3182243aa7

33. Johnson MJ, Wootton SA, Leaf AA, Jackson AA. Preterm birth and body composition at term equivalent age: A systematic review and meta-analysis. Pediatrics. 2012; 130(3): e640-e649. doi: 10.1542/ peds.2011-3379

34. Cooke RJ, Griffin I. Altered body composition in preterm infants at hospital discharge. Acta Paediatr. 2009; 98(8): 1269-1273. doi: 10.1111/j.1651-2227.2009.01354.x

35. Olhager E, Tornqvist C. Body composition in late preterm infants in the first 10 days of life and at full term. Acta Paediatr. 2014; 103(7): 737-743. doi: 10.1111/apa.12632

36. Rochow N, Fusch G, Mühlinghaus A, et al. A nutritional program to improve outcome of very low birth weight infants. Clin Nutr. 2012; 31: 124-131. doi: 10.0.3.248/j.clnu.2011.07.004

37. Senterre T, Rigo J. Optimizing early nutritional support based on recent recommendations in VLBW infants and postnatal growth restriction. J Pediatr Gastroenterol Nutr. 2011; 53(5): 536-542. doi: 10.1097/MPG.0b013e31822a009d

38. Graziano PD, Tauber KA, Cummings J, Graffunder E, Horgan MJ. Prevention of postnatal growth restriction by the implementation of an evidence-based premature infant feeding bundle. J Perinatol. 2015; 35(8): 642-649. doi: 10.1038/jp.2015.35

39. Senterre T, Rigo J. Reduction in postnatal cumulative nutritional deficit and improvement of growth in extremely preterm infants. Acta Paediatr. 2012; 101(2): e64-e70. doi: 10.1111/j.16512227.2011.02443.x

40. Olsen IE, Richardson DK, Schmid CH, Ausman LM, Dwyer JT. Intersite differences in weight growth velocity of extremely premature infants. Pediatrics. 2002; 110(6): 1125-1132. doi: 10.1542/ peds.110.6.1125

41. Piris Borregas S, López Maestro M, Torres Valdivieso MJ, Martínez Ávila JC, Bustos Lozano G, Pallás Alonso CR. Improving nutritional practices in premature infants can increase their growth velocity and the breastfeeding rates. Acta Paediatr. 2017; 106(5): 768-772. doi: 10.1111/apa.13788

42. Strommen K, Blakstad EW, Moltu SJ, et al. Enhanced nutrient supply to very low birth weight infants is associated with improved white matter maturation and head growth. Neonatology. 2015; 107(1): 68-75. doi: 10.1159/000368181

43. Blakstad EW, Strommen K, Moltu SJ, et al. Improved visual perception in very low birth weight infants on enhanced nutrient supply. Neonatology. 2015; 108(1): 30-37. doi: 10.1159/000381660

44. Moltu SJ, Blakstad EW, Strommen K, et al. Enhanced feeding and diminished postnatal growth failure in very-low-birth-weight infants. J Pediatr Gastroenterol Nutr. 2014; 58(3): 344-351. doi: 10.1097/MPG.0000000000000220

45. Blakstad EW, Moltu SJ, Nakstad B, et al. Enhanced nutrition improves growth and increases blood adiponectin concentrations in very low birth weight infants. Food Nutr Res. 2016; 60: 1-11. doi: 10.3402 /fnr.v60.33171

46. Hans DM, Pylipow M, Long JD, Thureen PJ, Georgieff MK. Nutritional practices in the neonatal intensive care unit: analysis of a 2006 neonatal nutrition survey. Pediatrics. 2009; 123(1): 51-57. doi: $10.1542 /$ peds.2007-3644

47. Andrews ET, Ashton JJ, Pearson F, Beattie RM, Johnson MJ. Early postnatal growth failure in preterm infants is not inevitable. Arch Dis Child Fetal Neonatal Ed. 2018. doi: 10.1136/archdischild-2018-315082

48. Goldberg DL, Becker PJ, Brigham K, et al. Identifying malnutrition in preterm and neonatal populations: Recommended indicators. J Acad Nutr Diet. 2018; 118(9): 1571-1582. doi: 10.1016/j. jand.2017.10.006

49. Wood AJ, Raynes-Greenow C, Carberry AE, Jeffery HE. Neonatal length inaccuracies in clinical practice and related percentile discrepancies detected by a simple length-board. J Paediatr Child Health. 2013; 49(3): 199-203. doi: 10.1111/jpc.12119

50. Pavageau L, Rosenfeld CR, Heyne R, et al. Valid serial length measurements in preterm infants permit characterization of growth patterns. J Perinatol. 2018; 38(12): 1694-1701. doi: 10.1038/ s41372-018-0242-4

51. Yakes Jimenez E, Abram J, Lamers-Johnson E, Steiber A. Baby steps toward improving the diagnosis and treatment of malnutrition in hospitalized pediatric patients: The Dietetics Practice-Based Research Network launches the malnutrition clinical characteristics validation and staffing optimization study. PNPG Building Block for Life. 2018; 41(3): 16-18. 